\title{
Pagpapakahulugan sa nobelang Noli Me Tangere: Isang hulwarang gabay sa pagtuturo
}

\author{
Mabalhin, Joel Q. $\triangle$ \\ Visayas State University - Baybay City, Philippines (joelqmabalhinbee7@gmail.com)

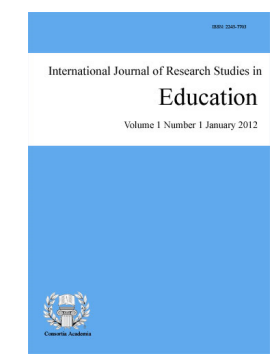

ISSN: 2243-7703 Online ISSN: 2243-7711

OPEN ACCESS

\section{Abstract}

Saklaw ng pag-aaral na ito ang pagsusuri sa mga piling pahayag na nakapaloob sa mga piling dalawampu't limang (25) kabanata ng nobelang Noli Me Tangere ni Dr. Jose Rizal sa paraang semantik at pragmatik. Sinuri ng mananaklisk ang buong aklat batay sa taglay na mahihirap na mga pahayag sa bawat kabanata. Dumaan ito sa tatlong analisis. Ang una ay nakatuon sa pagsusuri ng mga pahayag batay sa linggwistik na semantik na pagpapakahulugan. Ang ikalawang bahagi ay nakasentro naman sa pagsusuri batay sa pragmatik. Pinagbabatayan ang dalawang mahalagang nilalaman; linggwistikang nilalaman at pisikal na nilalaman. At ang ikatlong hakbang ay ang pagtukoy sa kaugnayan ng pagpapakahulugan batay sa semantik at pragmatik na pananaw. Binigyan ng kopya ang validator upang ebalideyt ang ginawang pagsusuri. Pagkatapos ay gumawa ang mananaliksik ng isang hulwarang gabay sa pagtuturo sa pagbasa gamit ang iba't ibang estratehiya sa pagtuturo.

Keywords: Noli Me Tangere; semantik; pragmatik; linggwistikang nilalaman; pisikal na nilalaman 


\section{Pagpapakahulugan sa nobelang Noli Me Tangere: Isang hulwarang gabay sa pagtuturo}

\section{Introduksyon}

“Ang panitikan ay nagpapayaman ng kaisipan at karanasan, nagpapalalim ng pag-uunawa, lumilinang ng kamalayang pansarili, panlipunan at pambansa, at nagpapahalaga ng mga karanasang magiging timbulan sa oras ng pangangailangan" (Rubin, 2001). Malinaw na ito ay isang kaparaanan sa pag-unlad ng isang bansa. Ang kabihasnan ay umunlad at magbunga ng mga mabubuting supling sa pamamagitan nito. Ang bawat pintig ng damdamin, ang bawat oras ng buhay ay parang hibla upang tayo sa sariling kakayahan malaki man o munti ay makapagbigay ng ating ambag sa pagpapabuti sa buhay.

Ayon pa rin kay Gonzales (qtd. Largo, 2007) ang panitikan ay nagpapahayag sa paraang nagpaparanas sa bumabasang kaisipan at damdamin ng manunulat at sa paraang abot-kaya ng mangangatha na nagsasaad na ito'y nagbibigay pagkakataon na maunawaan at maranasan ng mga mambabasa ang mga pagbabagong nagaganap sa bawat panahon. Idinagdag pa nito na itinatampok ang buhay, kaugalian, mga karanasan at ang kalagayan ng lipunan sa kinauukulang panahon. Salamin ito ng panahon ng kaligayahan, ng kalungkutan, ng pakikibaka, ng pagbabago, ng pagkakasundo at ng pag-unlad. Sa kabuuan, ito ang naglalarawan ng sangkatauhan.

Iniatas ng Republic Act \# 1425 na kilala sa Batas Rizal ang lahat ng paaralan, kolehiyo, pampubliko man o pribado na kailangang isama sa kanilang kurikulum ang tungkol sa mga ginawa at sinulat ni Jose rizal, partikular na ang kanyang mga Nobelang Noli Me Tanger at El Filibusterismo. Bilang Pagpapatupad sa batas, itinakda sa K to 12 na kurikulum ang pagtuturo ng mga akdang pampanitikan lalo na ang Noli Me Tangere sa ika-siyam na baitang sa sekundarya. Ito'y makatutulong sa pagtataguyod ng kontekstwalisasyon. - isa sa mga salient features ng bagong kurikulum na nagpapahalaga sa paggamit ng panitikang akda ng ating sariling manunulat. Katulad ng napatunayan ni Gorumba (2019), mas mabibigyang puwang ang mga lokal na manunulat at maiugnay ang mga nilalaman ng mga kwento sa aktwal na nakikita at nararanasan ng mga estudyante gaya ng kultura at lugar.

Ang bawat kabanata ng nobelang Noli Me Tangere ay kinapapalooban at napakayaman sa mga pahayag na nagtataglay ng malalim na pakahulugan, na kung hayaan ay napakarami at iba-ibang interpretasyon ang lumalabas na minsa'y lumihis ang mga ito sa nais palutangin ni Dr. Jose Rizal sa pamagat na "Noli Me Tangere" at sa nais niyang pamukaw at magpaalab sa damdaming nasyonalismo. Sa pag-aaral nga ni Alvarado (2019), sinabing, may mga akdang ginamitan ng matayutay na pahayag ang mga tauhan upang hindi lantarang maipahayag ang layunin katulad ng pag-aalsa. Mabisang malaman at mailapat ang semantika at pragmatikang pagsusuri ng mga ito nang sa gayun ay makita ang kaisahan ng mga guro sa Filipino na tamuhin ang nais palutangin ng pambansang bayani sa kanyang mga pahayag sa nobela.

\subsection{Semantik at pragmatik}

Sanligan ng pag-aaral na ito ang pinakapopular na teorya ni Lyons (2002) na nagsasabing "semantics is the study of those context-independent meaning elements which are tied to the linguistic expressions, i.e., part of the linguistic signs as such, and are invariant across all situations of use". Ibig sabihin, ang semantik ay nakapokus sa mga ambag sa pagpapakahulugang pangkalagayan sa mga pahayag o mga salita na inilaan mismo ng wika o lengguwahe. Sa kabilang banda ayon kay Lyon pa rin, "pragmatics would then deal with the specifying effects of various situational factors, and try to account for the meaning of specific utterance tokens". Nagpapahiwatig na ang pragmatika ay pumapaligid sa buong proseso sa pagkikilala o pagbabatid sa pagpapakahulugang pangkalagayan, ang buong interplay ng lahat ng iba't ibang linguistics at extralinguistics na mga salik.

Ang pagpapakahulugan sa kung ano ang nais ng tagapagsalita gamit ang tiyak na mga salita ay kadalasan maiimpluwensiyahan sa mga salik gaya ng palagay ng tagapakinig o nilalaman. Sa pragmatik ay may dalawang magkaibang nilalaman, linggwistikang nilalaman (linguistic context) at pisikal na nilalaman (physical context). 
Ang linggwistikang nilalaman, na minsan tinatawag na co-text ay lipon ng mga salita na pumapaligid sa mga leksikal na bagay sa tanong sa parehong parirala o pangungusap. Ang pisikal na nilalaman ay ang kinalalagyan ng ginagamit na mga salita, ang kalagayan at ang tiyempo din ng kanyang paggamit. Lahat ng mga ito ay tumutulong sa tumpak na pagpapakahulugan ng mga salita.

\subsection{Layunin}

Ang pag-aaral na ito ay naglayong masuri at mabibigyang pagpapakuhulugan ang mga piling pahayag na nakapaloob sa piling dalawampu't isang kabanata ng sa paraang semantik at pragmatik, at kaugnayan ng dalawa sa pagpapakahulugan nang sa gayon ay malinaw na matukoy ang kahulugan ng mga pahayag sa nobela.

\section{Metodolohiya}

\subsection{Desinyo ng pag-aaral}

Ginamit sa pag-aaral na ito ang Qualitative Research Method sa anyong pagsusuri sa nilalaman (content analysis) batay sa semantik at pragmatik na pagsusuri. Ayon kay Kerlinger (1986) ang content analysis ay isang mabisang paraan ng pag-aaral at pagsusuring komunikasyon na sistematikong maglalayon at madaling paraan ito sa pagsukat ng baryabol.

Nakatuon sa pagsusuri ng Noli Me Tangere na binubuo ng animnapu't (65) kabanata. Dito ginamit ang ginawang salin sa nobela sa wikang Filipino ni Enedina G. Villegas. Saklaw ng pag-aaral na ito ang pagsusuri sa mga piling pahayag na nakapaloob sa piniling dalawampu't isang (21) kabanata sa paraang semantik at pragmatik.

\subsection{Pagsusuri}

Sinipi ang 21 na may pahayag o mga pahayag na kailangang bigyang linaw dahil ito ang mga kabanata na hirap na hirap ang mga guro lalo na ang mga baguhan. Ibinatay ang pagpili ng mga pahayag sa unang 21 batay sa mga nangunguna sa ipinamigay na tseklist na pinagpilian ng anim (6) na mga guro mula sa pribadong paaralan (Kolehiyo at Hayskul), at tatlong (3) guro mula sa Kagawaran ng Edukasyon (Timugang Leyte). Kasama na rin ang apat na pu't limang (45) mag-aaral sa pribadong paaralan, at apat na pu't dalawa (42) mula Kagawaran ng Edukasyon.

Tatlong analisis ang ginawa sa pag-aaral na ito. Ang una ay nakasentro sa pagsusuri ng mga pahayag sa Noli Me Tangere batay sa linggwistik na semantik na pagpapakahulugan. Ang linggwistik ay nakaambag higit sa lahat sa pag-aaral sa pinakapusod na kahulugan o pag-uunawa sa bawat salita. Ang ikalawang bahagi ng analisis ay nakasentro naman sa pagsusuri batay sa pragmatik. Pinagbatayan nito ang mahahalagang nilalaman: Una, kontekstong linggwistika - minsan tinatawag na co-text ay lipon ng mga salita na pumapaligid sa mga leksikal na bagay sa parehong tanong o pangungusap; ikalawa, ang kontekstong pisikal - ang kinalalagyan ng mga salita, ang kalagayan ng kanyang paggamit, at tiyempo din. Ang ikatlong bahagi ay ang pagtukoy sa kaugnayan ng pagsusuri o pagpapakahulugan batay sa semantik at pragmatik na pananaw. Binigyan ng kopya ang mga tagasuri (experts) upang ebalideyt ang ginawang pagsusuri at pagpapakahulugan. Dalawa ang naging tagasuri sa pag-aaral na ito, parehong nagtapos ng Doctoral major in Filipino at pare-parehong ding may-akda ng maraming aklat sa Filipino na nakabase sa Cebu. Languages Department Head ng Cebu Doctors University, Lungsod ng Cebu ang isa, at ang isa naman ay Direktor ng Sentro ng Wika sa Cebu Normal University, Lungsod ng Cebu.

Ayon sa mga linggwista, mahirap hanggang sa kasalukuyan ang paghahanap ng kaugnayan sa dalawang mahalagang dibisyon sa pag-aaral sa kabuuan ng wika at pangungusap - ang semantik at pragmatik. May tiyak na alituntunin ang bawat isa sa pagsusuri ng mga pangungusap na naging dahilan ng pagkakaroon ng agwat. Subalit maaari pa ring iugnay ang dalawa sa paraang pagbibigay konsidera na ang dalawa ay parehong nakatuon 
Mabalhin, J. Q.

sa pag-aaral sa wika. Ang semantik ay ang pag-aaral at nagpapaliwanag sa konteksto ng isang pangungusap o diskurs, pati na rin sa kahalagahan ng konteksto sa pag-interpret ng wika. Samantalang, ang pragmatik ay kung paano nababago ng konteksto sa paraan ng pagsasalita o paghahatid ng mga kaalaman ng mga pahayag gamit ang salita.

\section{Resulta at talakayan}

Ang mga datos ay kaugnay sa paraan ng paglalahad at pagpapakahulugan ng mga piling pahayag ng akdang Noli Me Tangere bilang nobela sa semantik at pragmatik. Sa talahanayan sa ibaba, inilalahad ang pagbibigay-kahulugan sa mga piling pahayag batay sa semantik na pananaw sa ikalawang hanay. Pagbibigay-kahulugan naman batay sa pragmatik na pananaw: linggwistikang nilalaman at pisikal na nilalaman sa ikatlong hanay, at sa ikaapat na hanay ay ang kaugnayan ng pagpapakahulugang semantik at pragmatik na pananaw batay sa sagot at mungkahi ng mga tagasuri o eksperto.

\section{Talahanayan 1}

Semaktik at pragmatik na pagpapakahulugan at ang kaugnayan ng mga ito

\begin{tabular}{|c|c|c|c|}
\hline Pahayag & Semantik & Pragmatik & Kaugnayan \\
\hline $\begin{array}{l}\text { "Kilala ko ang bawat isa na } \\
\text { tulad ng pagkikilala ng isang } \\
\text { nagpapasusong ina sa } \\
\text { kanyang anak." }\end{array}$ & $\begin{array}{l}\text { Alam ko ang ginagawa ng bawat } \\
\text { isa tulad ng pagkakaalam ng isang } \\
\text { ina na nagpapalaki sa kanyang } \\
\text { mga anak. }\end{array}$ & $\begin{array}{l}\text { Linggwistikang Nilalaman: } \\
\text { Alam ko ang mga kasalanan ng } \\
\text { bawat isa. } \\
\text { Pisikal na Nilalaman: } \\
\text { Alam ko kung sino ang may } \\
\text { busilak na puso at kalooban. }\end{array}$ & $\begin{array}{l}\text { May kaugnayan sa diwa ng } \\
\text { pagkakaalam o pagkakabatid }\end{array}$ \\
\hline $\begin{array}{l}\text { "Ilang buwan pa at } \\
\text { sasang-ayon ka sa akin, iba } \\
\text { ang pamumuno sa Madrid at } \\
\text { iba naman sa Pilipinas" }\end{array}$ & $\begin{array}{l}\text { Ilang buwan pa lang at maniniwala } \\
\text { ka sa akin, ang mga mabubuting } \\
\text { pinuno na ipinapadala mula } \\
\text { Madrid ay magiging masama } \\
\text { pagdating dito sa Pilipinas. }\end{array}$ & $\begin{array}{l}\text { Linggwistikang Nilalaman: } \\
\text { Ilang buwan pa lang at maniniwala } \\
\text { ka sa akin, iba ang pamumuno sa } \\
\text { Pilipinas at iba naman sa Pilipinas. } \\
\text { Pisikal na Nilalaman: } \\
\text { Ilang buwan pa at maniniwala ka sa } \\
\text { akin, natutong maging masama at } \\
\text { naging sakim ang ipinapadalang } \\
\text { namamahala rito sa Pilipinas. }\end{array}$ & Walang kaugnayan \\
\hline $\begin{array}{l}\text { "Kung ang karunungan ang } \\
\text { pamana ng sangkatauhan, } \\
\text { ang magigiting lamang ang } \\
\text { maaaring magmana nito." }\end{array}$ & $\begin{array}{l}\text { Kung ang edukasyon ang pamana } \\
\text { sa bawat tao, ang matatapang } \\
\text { lamang ang bahaginan nito. }\end{array}$ & $\begin{array}{l}\text { Linggwistikang Nilalaman: } \\
\text { Kung ang edukasyon ang pamana } \\
\text { sa bawat tao, ang may mabubuting } \\
\text { hangarin lamang ang dapat } \\
\text { magkamit nito. } \\
\text { Pisikal na Nilalaman: } \\
\text { Kung ang edukasyon ay pamana ng } \\
\text { bawat isa, hindi ito dapat } \\
\text { makamtan sa taong may masamang } \\
\text { kalooban at baka gamitin ito sa } \\
\text { masasama. }\end{array}$ & Walang kaugnayan \\
\hline $\begin{array}{l}\text { "Datapwa't tandaan mong } \\
\text { hindi lahat ng kumikinang ay } \\
\text { ginto." }\end{array}$ & $\begin{array}{l}\text { Subalit tandaan mong hindi lahat } \\
\text { ng kumikinang ay mamahaling } \\
\text { bato. }\end{array}$ & $\begin{array}{l}\text { Linggwistikang Nilalaman: } \\
\text { Subalit tandaan mong hindi lahat na } \\
\text { iyong matutunan ay iyong } \\
\text { mapapakinabangan sa iyong buhay. } \\
\text { Pisikal na Nilalaman: } \\
\text { Subalit alalahanin mong hindi lahat } \\
\text { na iyong matututunan ay } \\
\text { makatutulong sa ikagaganda ng } \\
\text { iyong buhay. }\end{array}$ & Walang Kaugnayan \\
\hline $\begin{array}{l}\text { "Lahat ay mawawala gaya ng } \\
\text { pagkawala sa atin sa Europa. } \\
\text { Ang pinakagrabeng bahagi } \\
\text { nito'y tayo ang gumagawa ng } \\
\text { ating sariling kapahamakan." }\end{array}$ & $\begin{array}{l}\text { Lahat ay maglalaho tulad ng } \\
\text { paglaho natin (mga Kastila) sa } \\
\text { ating bansa. Ang pinakamahirap pa } \\
\text { nito'y tayo ang may kagagawan sa } \\
\text { ating pagkawala. }\end{array}$ & $\begin{array}{l}\text { Linggwistikang Nilalaman: } \\
\text { Maging mahirap tayong tulad ng } \\
\text { dinanas natin sa Europa. } \\
\text { Napakasakit pa nito'y tayo ang } \\
\text { naglalagay sa sariling kahirapan. } \\
\text { Pisikal na Nilalaman: } \\
\text { Maghihirap tayo tulad ng dati. At } \\
\text { ang patuloy na panlilinlang sa mga } \\
\text { indiyo (Pilipino) ay nagbubukas sa } \\
\text { kanilang mga mata sa katotohanan. }\end{array}$ & $\begin{array}{l}\text { May kaugnayn sa salitang } \\
\text { pagkawala at paglaho }\end{array}$ \\
\hline
\end{tabular}


Pagpapakahulugan sa nobelang Noli Me Tangere: Isang hulwarang gabay sa pagtuturo

Talahanayan 1 ...pagtutuloy

\begin{tabular}{|c|c|c|c|}
\hline Pahayag & Semantik & Pragmatik & Kaugnayan \\
\hline $\begin{array}{l}\text { "Tunay ngang katulad ng } \\
\text { libingang hinuhukay mo. Di } \\
\text { mo nalalaman ang iyong } \\
\text { nilululon at isinusuka." }\end{array}$ & $\begin{array}{l}\text { Totoo ngang kagaya ng mga patay } \\
\text { na hinukay mo. Di mo nalalaman } \\
\text { ang iyong sinusubo at iniluluwa. }\end{array}$ & $\begin{array}{l}\text { Linggwistikang Nilalaman: } \\
\text { Totoo ngang katulad ka ng mga } \\
\text { patay. Wala ka nang pakialam sa } \\
\text { mga buhay. } \\
\text { Pisikal na Nilalaman: } \\
\text { Totoo ngang katulad ka ng mga } \\
\text { patay. Wala ka nang pakiramdam. }\end{array}$ & Walang kaugnayan \\
\hline $\begin{array}{l}\text { "Hindi ko po siya isinama sa } \\
\text { mga Intsik. Minabuti ko pong } \\
\text { lunurin kaya't itinapon ko na } \\
\text { lang po sa ilog." }\end{array}$ & $\begin{array}{l}\text { Hiniwalay ko po siya sa libingan } \\
\text { ng mga Intsik. Para sa akin mabuti } \\
\text { pang lunurin sa ilog. }\end{array}$ & $\begin{array}{l}\text { Linggwistikang Nilalaman: } \\
\text { Hindi ko po siya inilibing kasama } \\
\text { ng mga hayop (turing sa mga } \\
\text { Intsik). Sa ilog ko na lang itinapon } \\
\text { dahil may dangal pa doon ang mga } \\
\text { patay. } \\
\text { Pisikal na Nilalaman: } \\
\text { Napakaaba po kapag inilibing ko } \\
\text { siya kasama ng mga di-bininyagan. } \\
\text { Mabuti pa sa ilog, walang } \\
\text { lalampastangan sa kanyang dangal. }\end{array}$ & Walang kaugnayan \\
\hline $\begin{array}{l}\text { "Iginalang ko ang ama dahil } \\
\text { sa kanyang anak, hindi ko } \\
\text { iginalang ang anak dahil sa } \\
\text { kanyang ama." }\end{array}$ & $\begin{array}{l}\text { Pinupuri ko ang ama sa mabuting } \\
\text { gawi ng kanyang anak, hindi ko } \\
\text { pinupuri ang mabuting gawi ng } \\
\text { anak dahil sa kanyang ama. }\end{array}$ & $\begin{array}{l}\text { Linggwistikang Nilalaman: } \\
\text { Maging mabuti ang anak kapag } \\
\text { mabuti ang ama. } \\
\text { Pisikal na Nilalaman: } \\
\text { May mabuting kalooban ang anak } \\
\text { kapag ganoon din ang nagpapalaki } \\
\text { sa kanya. }\end{array}$ & Walang kaugnayan \\
\hline $\begin{array}{l}\text { "Gamitin mo at maging } \\
\text { maligaya ka sa sarili mong } \\
\text { wika at huwag mong sirain } \\
\text { ang salitang Kastila, iyo'y } \\
\text { hindi para sa iyo." }\end{array}$ & $\begin{array}{l}\text { Pakinabangan mo at maging } \\
\text { Masaya ka sa wikang sarili at } \\
\text { huwag mong bastusin ang wikang } \\
\text { Kastila, iyo'y hindi bagay sa iyo. }\end{array}$ & $\begin{array}{l}\text { Linggwistikang Nilalaman: } \\
\text { Wala kang karapatang salitain ang } \\
\text { wikang Kastila, makontento ka sa } \\
\text { wikang sarili. } \\
\text { Pisikal na Nilalaman: } \\
\text { Masisira ang wikang Kastila kapag } \\
\text { pilitin mo (Pilipino) itong gamitin. } \\
\text { Sapat na ang wika mong mababa } \\
\text { ang uri. }\end{array}$ & $\begin{array}{l}\text { May kaugnayan sa paggamit } \\
\text { ng mga pariralang wikang } \\
\text { sarili at wikang Kastila }\end{array}$ \\
\hline $\begin{array}{l}\text { "Gamitin mo at maging } \\
\text { maligaya ka sa sarili mong } \\
\text { wika at huwag mong sirain } \\
\text { ang salitang Kastila, iyo'y } \\
\text { hindi para sa iyo." }\end{array}$ & $\begin{array}{l}\text { Pakinabangan mo at maging } \\
\text { Masaya ka sa wikang sarili at } \\
\text { huwag mong bastusin ang wikang } \\
\text { Kastila, iyo'y hindi bagay sa iyo. }\end{array}$ & $\begin{array}{l}\text { Linggwistikang Nilalaman: } \\
\text { Wala kang karapatang salitain ang } \\
\text { wikang Kastila, makontento ka sa } \\
\text { wikang sarili. } \\
\text { Pisikal na Nilalaman: } \\
\text { Masisira ang wikang Kastila kapag } \\
\text { pilitin mo (Pilipino) itong gamitin. } \\
\text { Sapat na ang wika mong mababa } \\
\text { ang uri. }\end{array}$ & $\begin{array}{l}\text { May kaugnayan sa paggamit } \\
\text { ng mga pariralang wikang } \\
\text { sarili at wikang Kastila }\end{array}$ \\
\hline $\begin{array}{l}\text { "Isasagawa ninyo ang bagay } \\
\text { na minsan kong } \\
\text { pinapangarap, pangarap ng } \\
\text { isang baliw." }\end{array}$ & $\begin{array}{l}\text { Isasagawa din ni Ibarra ang nais ni } \\
\text { P. Tasyo, ang nais ng taong wala } \\
\text { sa katinuan. }\end{array}$ & $\begin{array}{l}\text { Linggwistikang Nilalaman: } \\
\text { Nangarap din si P. Tasyo na } \\
\text { pag-aaralin ang mga kabataang } \\
\text { Pinoy noon, ngunit walang } \\
\text { nagtiwala sa kanya dahil itinuturing } \\
\text { siyang rebelde. } \\
\text { Pisikal na Nilalaman: } \\
\text { Nangarap din si P. Tasyo katulad } \\
\text { ng pangarap ni Ibarra na uunlad } \\
\text { ang kaalaman ng mga Pilipino, } \\
\text { subalit dahil sa taliwas ito sa } \\
\text { layunin ng mga kastila, kailanman } \\
\text { hindi ito maisakatuparan. }\end{array}$ & Walang kaugnayan \\
\hline $\begin{array}{l}\text { "Ang pagsasaya'y di } \\
\text { nangangahulugang gawin } \\
\text { nating hangal ang ating } \\
\text { sarili." }\end{array}$ & $\begin{array}{l}\text { Ang katuwaa'y hindi kailangang } \\
\text { gawin nating katawa-tawa ang } \\
\text { ating sarili. }\end{array}$ & $\begin{array}{l}\text { Linggwistikang Nilalaman: } \\
\text { Hindi kailangang gumastos tayo } \\
\text { nang malaki sa pagdiriwang upang } \\
\text { tayo'y maging masaya. } \\
\text { Pisikal na Nilalaman: } \\
\text { Hindi kailangang magwaldas tayo } \\
\text { ng malaking halaga upang maging } \\
\text { masaya ang pagdiriwang. }\end{array}$ & Walang kaugnayan \\
\hline
\end{tabular}


Mabalhin, J. Q.

Talahanayan 1 ...pagtutuloy

\begin{tabular}{|c|c|c|c|}
\hline Pahayag & Semantik & Pragmatik & Kaugnayan \\
\hline $\begin{array}{l}\text { "Kung ako ang tatanungin, } \\
\text { higit na nakatutuwa ang } \\
\text { sermon kaysa komedya" }\end{array}$ & $\begin{array}{l}\text { Sa ganang akin, lubos na } \\
\text { nakakatawa ang sermon (ng pari) } \\
\text { kaysa komedya (sa palabas). }\end{array}$ & $\begin{array}{l}\text { Linggwistikang Nilalaman: } \\
\text { Para sa akin, may kabuluhan pa ang } \\
\text { komedya kaysa sermon ng pari. } \\
\text { Pisikal na Nilalaman: } \\
\text { Para sa akin, may natutunan pa tayo } \\
\text { sa komedya kaysa sermon ng pari. }\end{array}$ & $\begin{array}{l}\text { May kaugnayan sa paggamit } \\
\text { ng mga salitang sermon at } \\
\text { komedya. }\end{array}$ \\
\hline $\begin{array}{l}\text { "Na sinumang may dila ay } \\
\text { maaaring magkamali kaya't } \\
\text { ang hatol ay higit pang } \\
\text { maraming natatagong } \\
\text { katotohanan sa kasaysayan." }\end{array}$ & $\begin{array}{l}\text { Na sinumang magsasabi ay } \\
\text { maaaring magkamali kaya't ang } \\
\text { iginawad na hukom ay lubha pa sa } \\
\text { natatagong katunayan sa } \\
\text { kasaysayan. }\end{array}$ & $\begin{array}{l}\text { Linggwistikang Nilalaman: } \\
\text { Kahit sino ay magkakamali kaya't } \\
\text { sinuman ang magpapatunay o } \\
\text { magpapatotoo ay malayo pa rin sa } \\
\text { katotohanan. } \\
\text { Pisikal na Nilalaman: } \\
\text { Lahat tayo'y nagkakamali kaya't } \\
\text { sinumang mangangatwirang tama } \\
\text { ay wala itong kaganapan. }\end{array}$ & Walang kaugnayan \\
\hline $\begin{array}{l}\text { "Kailangan kong manalig sa } \\
\text { Diyos sapagkat nawala na } \\
\text { ang tiwala ko sa tao. }\end{array}$ & $\begin{array}{l}\text { Kinakailangan kong magtiwala sa } \\
\text { Panginoon sapagkat wala na akong } \\
\text { tiwala sa tao. }\end{array}$ & $\begin{array}{l}\text { Linggwistikang Nilalaman: } \\
\text { Sa Diyos lamang ako higit na } \\
\text { magtitiwala. } \\
\text { Pisikal na Nilalaman: } \\
\text { Sa Diyos lamang ako dapat } \\
\text { magtitiwala. }\end{array}$ & $\begin{array}{l}\text { May kaugnayan sa salitang } \\
\text { tiwala }\end{array}$ \\
\hline $\begin{array}{l}\text { "Ang kamay ng Diyos ay } \\
\text { laging nakaamba at } \\
\text { kinakailangang maging bulag } \\
\text { ka upang iyo'y di makita." }\end{array}$ & $\begin{array}{l}\text { Ang kapangyarihan ng Diyos ay } \\
\text { nakahanda para sa atin at } \\
\text { kinakailangang mawalan ka ng } \\
\text { paningin upang ito'y di mo makita. }\end{array}$ & $\begin{array}{l}\text { Linggwistikang Nilalaman: } \\
\text { Napakamatulungin ng Diyos sa tao, } \\
\text { at ito'y di dapat abusuhin. } \\
\text { Pisikal na Nilalaman: } \\
\text { Ang kapangyarihan ng Diyos ay } \\
\text { palaging nakalaan para sa tao, hindi } \\
\text { dapat ito abusuhin. }\end{array}$ & Walang kaugnayan \\
\hline $\begin{array}{l}\text { "Kami'y dumating dito na } \\
\text { walang muwang sa pulong } \\
\text { ito at umuuwi kapag malapit } \\
\text { nang maging lubos ang } \\
\text { aming kaalaman tungkol sa } \\
\text { bansa." }\end{array}$ & $\begin{array}{l}\text { Kami’y (mga kastila) dumating } \\
\text { dito na walang alam sa bansang ito } \\
\text { at babalik kapag malapit nang } \\
\text { maging ganap ang aming kabatiran } \\
\text { tungkol sa Pilipinas. }\end{array}$ & $\begin{array}{l}\text { Linggwistikang Nilalaman: } \\
\text { Kami’y ipinadala dito upang } \\
\text { ipapatupad ang mga batas na galing } \\
\text { sa Espanya at pauuwiin kapag } \\
\text { sumuway sa anumang batas. } \\
\text { Pisikal na Nilalaman: } \\
\text { Kami'y ipinapadala rito upang } \\
\text { maging tagapagpatupad ng mga } \\
\text { batas galing Espanya at pauuwiin } \\
\text { kapag sumuway sa mga ito. }\end{array}$ & Walang kaugnayan \\
\hline $\begin{array}{l}\text { "Sa araw na ito, sa unang } \\
\text { pagkakataon ay nasaksihan } \\
\text { ko kung paano ang magiging } \\
\text { isang mabuting Kastila na } \\
\text { mananatiling isang mabuting } \\
\text { Pilipino." }\end{array}$ & $\begin{array}{l}\text { Sa araw na ito, sa unang } \\
\text { pagkakataon ay nararamdaman ko } \\
\text { kung paano ang maging isang } \\
\text { mabuting pinuno na mananatiling } \\
\text { mabuti sa nasasakupan. }\end{array}$ & $\begin{array}{l}\text { Linggwistikang Nilalaman: } \\
\text { Sa pagkakataong ito, nababatid } \\
\text { kong maraming mabubuting } \\
\text { Pilipinong dapat makaranas ng } \\
\text { mabuting pamamahala. } \\
\text { Pisikal na Nilalaman: } \\
\text { Sa pagkakataong ito, nababatid } \\
\text { kong isang malaking kahihiyan ang } \\
\text { paggawa ng katiwalian sa bayang } \\
\text { may mabubuting mamamayan. }\end{array}$ & Walang kaugnayan \\
\hline $\begin{array}{l}\text { "Hindi na, salamat. Bastante } \\
\text { na ako sa sariling panaginip } \\
\text { at kalokohan." }\end{array}$ & $\begin{array}{l}\text { Huwag na, salamat. Kontento na } \\
\text { ako sa sariling pangarap at } \\
\text { kagaguhan. }\end{array}$ & $\begin{array}{l}\text { LinggwistikangNilalaman: } \\
\text { Salamat na lang at ayaw kong } \\
\text { makikisali sa inyong walang } \\
\text { katuturang pagdiriwang. } \\
\text { Pisikal na Nilalaman: } \\
\text { Salamat na lang at ayaw kong } \\
\text { waldasin ang aking yaman at } \\
\text { panahon sa walang katuturang } \\
\text { pagdiriwang. }\end{array}$ & Walang kaugnayan \\
\hline
\end{tabular}


Talahanayan 1 ...pagtutuloy

\begin{tabular}{|c|c|c|c|}
\hline Pahayag & Semantik & Pragmatik & Kaugnayan \\
\hline $\begin{array}{l}\text { "Kapag ang ganitong } \\
\text { kamalasan ang sumapit sa } \\
\text { isang pamilya. Lahat sila'y } \\
\text { malilipol. Lubusang } \\
\text { mamamatay ang isang puno } \\
\text { kapag tinamaan ng kidlat. }\end{array}$ & $\begin{array}{l}\text { Kapag ang ganitong kapahamakan } \\
\text { ay dumating sa isang tahanan. } \\
\text { Lahat sila'y mapapahamak. } \\
\text { Napakasakdal para sa isang puno } \\
\text { kapag tinamaan ng kidlat. }\end{array}$ & $\begin{array}{l}\text { Linggwistikang Nilalaman: } \\
\text { Ang bawat kasapi ng pamilya ay } \\
\text { masunurin, dahil napakadelikado } \\
\text { kapag sumuway sa kapangyarihan } \\
\text { lalo na kapag ang ama ang } \\
\text { mangunguna. } \\
\text { Pisikal na Nilalaman: } \\
\text { Ang buong pamilya ay dapat buo } \\
\text { ang pasyang sumunod sa } \\
\text { ipinapatupad na batas, dahil } \\
\text { mapapahamak ito kung sumuway } \\
\text { lalo na ang haligi ng tahanan }\end{array}$ & Walang kaugnayan \\
\hline $\begin{array}{l}\text { "Magtatamo tayo ng } \\
\text { katarungan, kapag hindi, ako } \\
\text { ang unang mamamatay sa } \\
\text { paghihimagsik na ating } \\
\text { sisimulan }\end{array}$ & $\begin{array}{l}\text { Magkakamit tayo ng katarungan, } \\
\text { at kung hindi, ako ang unang } \\
\text { masawi sa labang ating } \\
\text { uumpisahan. }\end{array}$ & $\begin{array}{l}\text { Linggwistikang Nilalaman: } \\
\text { Kailangan nating magtagumpay, } \\
\text { handa kong isasakripisyo ang aking } \\
\text { sarili para sa ating bayan. } \\
\text { Pisikal na Nilalaman: } \\
\text { Kailangan nating makabawi, handa } \\
\text { kong ibuwis ang aking buhay para } \\
\text { sa ating bayan. }\end{array}$ & Walang kaugnayan \\
\hline $\begin{array}{l}\text { "Pakatandaan mo Clarita, } \\
\text { huwag kang pakakasal sa } \\
\text { lalaking walang pantalon, ni } \\
\text { aso, di ka igagalang." }\end{array}$ & $\begin{array}{l}\text { Tandaan mo Clarita, huwag kang } \\
\text { sasama sa lalaking walang } \\
\text { paninindigan, ni hayop di ka } \\
\text { papansinin }\end{array}$ & $\begin{array}{l}\text { Linggwistikang Nilalaman: } \\
\text { Dapat mo itanim sa iyong isip } \\
\text { Clarita, huwag kang pakakasal sa } \\
\text { taong di tumayo sa sariling paa } \\
\text { dahil hindi ka maging masaya. } \\
\text { Pisikal na Nilalaman: } \\
\text { Dapat mong tandaan Clarita, huwag } \\
\text { kang magkamaling pakakasal sa } \\
\text { taong walang isang salita dahil } \\
\text { hindi ka maging masaya. }\end{array}$ & Walang kaugnayan \\
\hline
\end{tabular}

Sa Talahanayan 1, sa semantik na hanay, napatunayan na sa pagpapakahulugan ay karaniwang iniugnay sa kahulugan ang mga salita na madalas ay hinahanap natin sa mga talatinigan. Hindi kailangang lumayo sa mga salitang ginagamit upang madali at lubos na maintidihan ang pahayag ng isang tao. Binigyang-diin nga ni Lyons (2002), na "semantics would focus on those contributions to the situational interpretations of utterances and texts which are provided by the language itself".

Sa ikatlong hanay, napatunayang malaki ang papel na ginagampanan ng pragmatik sa paglilinaw sa kahulugan ng isang pahayag, sa pamamagitan ng linggwistikang nilalaman, at pisikal na nilalaman, dito nilinaw kung paano iniimpluwensiyahan ng mga konteksto ang paraan ng paghahatid ng mga impormasyon ng mga pangungusap, maliban sa mga bagay sa paligid, kasama ang mga aksyong nagaganap, kailangan ding isaalang-alang ang kultura at kaalaman ng nagsasalita at nakikinig. Sabi nga ni Carnap (1975), "pragmatics would be the descriptive study of how language is actually used; how concepts are in fact applied to different situations, and what interpretations are arrived at by real language users". Sa bahagi ng mananaliksik kung saan malayo ang agwat ng kanyang panahon kaysa panahon ng may-akda, malaking tulong ang kanyang pagbabasa sa buhay ng may-akda upang kanyang mabatid ang katotohanan sa buhay nito.

Sa pag-uugnay ng semantik at pragmatik na pagpapakahulugan, napapatunayan na halos kalahati sa mga pahayag ay may kaugnayan ngunit marami ang wala. Mahirap iugnay ang semantik sa pragmatik, dahil ang una ay tumutukoy sa pag-aaral ng kahulugan mismo ng salita, samantalang ang huli ay tumutukoy sa kahulugan ng kaugnayan ng mga salita sa buong pangungusap. Mahirap ding gamitin ang semantik sa mga masisining at matalinghagang pahayag, samantalang, ito naman ang isa sa mga maraming paraan ng pagpapakahulugang pragmatik. Katulad ng sinabi ni Lyons (2002), "semantics be exclusively concerned with those meaning elements that have referential or cognitive functions, whereas the study of all various social, emotive, practical and associative aspects be relegated to pragmatics". Inaamin ng mga linggwista na hanggang ngayon ang kaugnayan 
Mabalhin, J. Q.

ng semantik at pragmatik ay isa sa mga maiinit na pinagtatalunan tungkol sa konsern sa linggwistika. Sinabi ni Abrusan (2019) na maraming manunulat ang nagsasabi na ang proseso ng semantik at pragmatik kapag pinag-uugnay, maghahatid ito ng kalituhan at kawalan ng gramar.

\section{Konklusyon at rekomendasyon}

Ang Pagpapakahulugang semantik sa nobelang "Noli Me Tangere" ay nagsasaad ng unang hakbang sa paglalayag sa pag-iintindi ng mga pahayag na may itinatagong kakaibang kahulugan. Ito ang magdadala sa mga mambabasa sa pangunahing paraan sa pagtitimbang-timbang sa kanyang pag-uunawa sa mga pahayag na halatang may nakatagong dapat halungkatin ng mga mambabasan. Sabi nga ni Landy (1984), ang pagsusuri ay pagbibigay ng pagkakataon ng umakda na maibigay nang buong linaw sa mga nakatagong kahulugan para sa mga mambabasa. Ang semantik na pananaw bilang pangunahing paraan sa pagpapakahulugan ay nagbibigay ng literal na mukha ng diwa sa mga salitang ginagamit. Hindi ito nangangailangan ng malalim at mala-kritikong paraan ng pagbabasa upang makuha ang diwa ng pahayag. Sa semantik na pagpapakahulugan, tayo'y ng may-akda upang mabubuo sa ating damdamin ang pagnanais na tunguhin at tahakin ang landas na nakita ni Rizal para sa atin. Nagtataglay ng kahulugan ang pahayag sa pananaw na ito ng hindi masyadong nakababagot sa ating diwa upang mas lalo nating pananabikan ang bawat yugto ng pangyayari.

Malinaw ang isinasaad ng pagpapakahulugang pragmatik na naghahamon sa mga guro, mag-aaral at ibang mambabasa na tarukin o sisirin ang tunay na kahulugan ng ilan sa mga pahayag sa nobela upang matamo ang layunin nitong makatulong sa pagliliyab ng sangkurot na damdaming nasyonalismo sa ilan nating kababayan lalo na sa mga kabataan. Napakahalaga ang pagpapakahulugang pragmatik upang makikita sa iba't ibang anggulo o kaparaanan ang nasa puso ng may-akda na nais niyang ipapabatid maging sa kahuli-hulihang Pilipinong lahi sa mundong ibabaw. Kung ang pagpapakahulugan ay dadaanin sa napakalimitadong paraan, maaaring lilihis ito ng tunguhin at maging isang babasahin lamang siya na katulad ng marami na pampalipas oras lamang. Ang nobelang ito ang nagpapatuyo sa utak ng may-akda upang pukawin ang mga katutubo sa maling pag-usbong ng kanilang pagkatao, kaya naman, nangangailangan din ito ng madugong pagninilay upang magpang-abot ang diwa at puso ni Jose Rizal at sa mga mambabasa.

Ang kabatiran sa kaugnayan ng pagpapakahulugang semantik at pragmatik ay napakahalaga. Ito ay nagsasaad ng masusing paglilimi upang makita ang pinakakaibuturang kahulugan na siyang inaasahan ng pambansang bayani na si Jose Rizal. Sa pagbabasa at pagsusuri ng buong nobela , at batay na rin sa kasaysayan sa buhay ng may-akda, ang paggamit niya ng mga pahayag na maaaring may dalawa o mahigit pang kahulugan, may kaugnayan man ito o wala ay upang ito'y hindi masyadong mapansin ng mga Kastila kahit pa man may kalabuan sa pag-iintindi ng mga katutubo, dahil kung hindi, hindi ito aabot o mababasa sa ating henerasyon at sa sunod pang henerasyon.

Ang nobela ay punong-puno ng kaalaman na maaaring batayan ng tao sa kanyang interaksyon sa kapwa at kapaligiran. Taglay ng mga tauhan ang iba't ibang katangian at kaugalian na lumulutang sa kani-kanilang pahayag. Sa pagsusuri gamit ang semantik at pragmatik na pamamaraan, makatitiyak ang mga mambabasa ng malalim at mapakinabangang kaisipan at saloobin. Katulad ng nobelang Noli Me Tangere na may layuning manggising at magpalalim ng damdaming nasyonalismo, kailangang masuri at maarok ang kaibuturang katuturan nito upang maisakatuparan ang minimithing layunin.Dito't higit na kailangan ang kaalaman sa semantik at pragmatik na pananaw upang mapagtimbang-timbang ang prosesong pagpapakahulugang nagaganap sa isipan ng mambabasa.

Iminungkaihng dapat ganayakin ang mga mag-aaral sa pagbabasa ng akdang pampanitikan upang umunlad ang kasanayan sa pag-uunawa at pagpapakahulugan. Dapat gumamit din ang guro ng iba't ibang paraan sa pagbibigay ng mga kasanayan na susukat sa kakayahan ng mga mag-aaral upang magdulot ng kawilihan sa kanila. May karugtong ang nobelang ito, ang El Filibusterismo, mangyari'y dapat pag-aralan din ito upang lubos na maunawaan at lalong umalab sa puso ng bawat mag-aaral ang nasyonalismong damdaming nais ipamahagi ni 
Dr. Jose P. Rizal sa kanyang mga akda.

\section{Sanggunian}

Abrusan, M. (2019). Semantic anomaly, pragmatic infelicity, and ungrammatically. Annual Review of Linguistics, 5, 329-351. https://doi.org/10.1146/annurev-linguistics-011718-011938

Alvarado, E. (2019). Luha ng buwaya: Wika at isyung sosyo-politikal ng mga magsasaka. International Journal of Research Studies in Education, 8(4), 67-75. https://doi.org/10.5861/ijrse.2019.4901

Carnap, R. (1972). Philosophy dictionary of arguments. Retrieved from http://philosophy-science-humanities-controversies-com/listview-list.php?concept=Pragmatics

Gorumba, J. (2019). Translation and analysis of Jesus Sanchez short stories. International Journal of Research Studies in Education, 8(4), 39-45. https://doi.org/10.5861/ijrse.2019.4904

Kerlinger, F. N. (1986). Foundation of behavioural research (3rd ed.). New York: Holt, Rinehart, and Winston.

Landy, J. V. SJ. (1984). Insight, A study of short story. Manila: Jesuit Educational Association.

Largo, R. (2007). Analisis sa nobela at pelikulang Noli Me Tanger [Doctoral dissertation]. Cebu Normal University, Cebu City, Philippines.

Lyons, J. (2002). Linguistic semantics: An introduction. Cambridge, UK: The Pitt Building.

Official Gazette of the government of the Philippines, Republic Act Number 1425, 1956. Rizal's Law. Retrieved from http://officialgazette.gov.ph/1956/06/12/republic-act-no-1425/

Parker, F., \& Railey, K. (2000). Linguistics for non-linguistics (3rd ed.). Needham Heights, MA: Pearson Education.

Rubin, L., Cassanova, A., et al. (2001). Panitikan sa Pilipinas. Manila: Rex Book Store.

Villegas, E. (2004). Noli me tangere, J Rizal. Quezon City: SIBS Publishing House. 
Mabalhin, J. Q.

28 Consortia Academia Publishing (A partner of Network of Professional Researchers and Educators) 